\title{
Pengaruh Pengetahuan, Pelatihan, dan Sikap Kerja Terhadap Prestasi Kerja Karyawan di PT. SENA
}

\author{
Jesika Yuanita Febriani ${ }^{1}$, Tony Susilo Wibowo ${ }^{2}$ \\ Universitas PGRI Adi Buana Surabaya ${ }^{1,2,3}$ \\ Jesikayf04@gmail.com
}

\begin{abstract}
ABSTRAK
Prestasi kerja terjadi karena pengetahuan yang dimiliki oleh karyawan. Pengetahuan yang luas yang dimiliki karyawan didapat melalui pelatihan-pelatihan yang diikuti oleh karyawan secara mandiri ataupun diadakan oleh perusahaan. Sikap kerja juga akan menjadi pendorong terbentuknya prestasi kerja karyawan. Sikap karyawan yang disiplin dan jujur dalam menyelesaikan tugas akan membantu meningkatkan prestasi kerja karyawan sendiri. sebanyak 70 Karyawan PT. SENA dijadikan populasi dan sampel. Sampel jenuh dijadikan sebagai teknik pengambilan sampel. Kuesioner disebar ke responden kemudian jawaban responden akan dianalisis data menggunakan analisis regresi linier berganda. Ditemukan hasil variabel pengetahuan, pelatihan dan sikap kerja mempunyai pengaruh signifikan pada variabel prestasi kerja karyawan. Kemudian ditemukan hasil lain yaitu variabel pengetahuan, pelatihan dan sikap kerja memiliki pengaruh simultan pada variabel prestasi kerja karyawan di PT. SENA.
\end{abstract}

Kata kunci: Pengetahuan, Pelatihan, Sikap Kerja dan Prestasi Kerja

\begin{abstract}
Job performance occurs because of the knowledge possessed by employees. Extensive knowledge possessed by employees is obtained through trainings that are participated by employees independently or held by the company. Work attitude will also be a driving force for employee performance. The attitude of employees who are disciplined and honest in completing tasks will help improve employee's own work performance. as many as 70 employees of PT. SENA is used as population and sample. Saturated samples are used as a sampling technique. Questionnaires are distributed to respondents then the respondents' answers will be analyzed by data using multiple linear regression analysis. The results found knowledge, training and work attitude variables have a significant effect on employee performance variables. Then found other results namely the variables of knowledge, training and work attitude have a simultaneous influence on the variable work performance of employees at PT. SENA.
\end{abstract}

Keywords: Knowledge, Training, Work Attitudes, and Job Performance 
Sumber daya manusia diperusahaan menjadi suatu hal yang penting. Hal ini dikarenakan sumber daya manusia yang unggul akan membantu perusahaan berkembang dan mendapatkan laba lebih banyak lagi. oleh karena itu, banyak perusahaan melakukan pengembangan pada sumber daya manusia. Pengembangan ini berguna untuk meningkatkan prestasi kerja baik bagi karyawan maupun perusahaan.

Salah satunya PT. Solusi Energy Nusantara (SENA). Perusahaan ini menjadi anak perusahaan PT. PGAS Solution dan bagian dari PGN Group. Perusahaan di Indonesia yang bergerak dibidang transmisi dan pendistribusian gas bumi. PT. SENA merasa sadar akan pentingnya menjaga prestasi kerja para karyawannya. Prestasi kerja bisa juga mengalami penurunan. Penurunan ini disebabkan karena rendahnya pengetahuan yang dimiliki karyawan, kurangnya pelatihan yang diadakan oleh perusahaan serta sikap kerja karyawan yang kurang disiplin dalam menyelesaikan tugas.

Prestasi kerja sendiri diartikan sebagai hasil dari semangat kerja karyawan dalam menyelesaikan tugas yang dibebankan perusahaan. Prestasi kerja dapat diraih dengan berbagai cara misalnya dengan memperluas pengetahuan karyawan.

Pengetahuan karyawan harus terus ditambah agar karyawan tahu akan segala hal yang dibutuhkan perusahaan untuk maju menjadi yang terdepan. Pengetahuan bisa diperoleh dari seberapa aktifnya karyawan bertukar pendapat atau ilmu dengan rekan kerja atau orang lain. Dengan bertukar pendapat atau informasi antar karyawan lain akan semakin menambah pengetahuan yang luas. Pengetahuan karyawan juga diperoleh dari pelatihan-pelatihan.

Pelatihan kerja karyawan bisa membantu untuk meningkatkan prestasi kerja karyawan. Dengan lebih sering mengikutsertakan karyawan dalam pelatihan atau seminar akan membuat karyawan semakin berprestasi. Prestasi kerja juga bisa disebabkan oleh sikap kerja karyawan.

Sikap kerja karyawan yang disiplin dan jujur menjadi kunci utama dalam meraih prestasi kerja. Sebaliknya karyawan yang mempunyai sikap yang buruk dan kurang optimis akan menurunkan prestasi kerja. Sikap kerja juga tergantung pada perilaku karyawan lain. Apabila perilaku karyawan diperusahaan banyak yang positif atau baik akan menjadikan karyawan lainnya menjadi ikut positif dan disiplin sehingga terciptanya prestasi kerja karyawan semakin cepat. Oleh karena itu banyak perusahaan yang berlomba-lomba meningkatkan pretasi kerja karyawan. Dari latar belakang yang dipaparkan diatas akan diambil rumusan masalah yaitu:

1. Apakah pengetahuan memiliki pengaruh pada prestasi kerja karyawan PT. SENA?

2. Apakah pelatihan memiliki pengaruh pada prestasi kerja karyawan PT. SENA?

3. Apakah sikap kerja memiliki pengaruh pada prestasi kerja karyawan PT. SENA?

4. Apakah pengetahuan, pelatihan dan sikap kerja memiliki pengaruh secara simultan pada prestasi kerja karyawan di PT. SENA?

\section{TINJAUAN PUSTAKA \\ Landasan Teori \\ Pengetahuan}

Notoatmodjo (2012) dalam Fuadi (2016) pengetahuan diartikan sebagai bertambahnya suatu informasi seseorang yang sebelumnya didapat melalui penglihatan atau pendengaran seseorang pada suatu objek.

Pengetahuan juga diartikan sebagai sebuah keahlian karyawan yang diperoleh dari sebuah pemahaman, penghayatan dan pengenalan pada suatu pekerjaan (Robins and Judge, 2009) dalam Suhartini, 2016).

Jadi ditarik kesimpulan pengetahuan diartikan sebagai sikap seseorang tau akan sesuatu hal yang didapat dari apa yang karyawan lihat dan dapatkan.

Azwar (2015) dalam Putri (2018) indikator pengetahuan yaitu :

1. Mempunyai fikiran yang analistis

Setiap orang mempunyai kemampuan untuk memilah bagian-bagia dari sesuatu hal. Kemudian bagian-bagian tersebut dikaitkan.

2. Memiliki fikiran yang konseptual

Kemahiran seseorang untuk melakukan identifikasi pada suatu pola sehingga informasi yang kurang jelas akan muncul menjadi nampak dan jelas.

3. Mempunyai pengetahuan tentang pekerjaan Melalui informasi dan pengalaman kerja yang dimiliki karyawan akan semakin menambah pengetahuan karyawan itu sendiri. 


\section{Pelatihan}

Widodo (2015:82) pelatihan yaitu segala kegiatan yang dilakukan oleh tiap individu dengan tujuan meningkatkan kemampuan dan pengetahuan karyawan.

Pelatihan juga berarti suatu bentuk kegiatan yang dimana kepribadian dan perilaku karyawan diubah menjadi lebih baik lagi sehingga akan membantu tercapainya tujuan perusahaan.

Ditarik kesimpulan pelatihan artinya sebuah bentuk usaha untuk meningkatan kualitas dan kemampuan kerja menjadi lebih baik dari sebelumnya.

Fanani dan Mosesn (2011) indikator pelatihan yaitu:

1. Type atau jenis dari pelatihan

Pelatihan atau training harus sesuai yang dibutuhkan perusahaan serta melihat juga waktu dan pendanaan.

2. Materi yang diberikan saat pelatihan

Materi harus sesuai dengan apa yang dilatih atau disesuaikan dengan jenis pelatihannya.

\section{Sikap Kerja}

Schermerhorn, dkk dalam Muhammad Muhson (2017:21) sikap yaitu respon karyawan pada lingkungan tempat kerjanya.

Kemudian Kerja sendiri artinya pikiran atau tenaga yang dikorbankan untuk mendapatkan suatu timbal balik atau imbalan. Dari pengorbanan tersebut akan menghasilkan suatu produk atau jasa. (Hasibuan, 2001:94). Jadi sikap kerja yaitu suatu tindakan yang dilakukan oleh karyawan selain bertujuan untuk menjaga nama baik karyawan sendiri juga sebagai suatu respon karyawan pada lingkungan kerjanya.

Menurut Azwar (2012:30) Indikator dari sikap kerja yaitu :

1. Harus mampu mengendalikan diri

Sikap karyawan harus dikontrol. Jadi ketika karyawan akan melakukan suatu tindakan harus memikirkan tindakannya tersebut agar tidak merugikan karyawan lain dan perusahaan.

2. Kerja yang fleksibel

Perusahaan harus mampu mengendalikan jam kerja karyawan agar penjadwalan jam kerja terpenuhi.

3. Komitmen pada pekerjaan

Karyawan yang mempunyai komitmen kerja akan kuat kemauannya dalam tetap bertahan di perusahaan tersebut.

\section{Prestasi Kerja}

Mangkunegara (2013:67) Prestasi kerja yaitu buah hasil kerja keras dari penyelesaian tugas yang diberikan perusahaan. hasil kerja secara kualitas dan kuantitas.

Prestasi kerja diartikan sebagai sebuah hasil yang diraih karyawan setelah menyelesaikan tugas yang dibebankan kepada karyawan tersebut. (Hasibuan, 2008:8).

Mangkunegara (2013:18) Indikator prestasi kerja yaitu:

1. Quality

Kualitas dilihat dari karyawan yang teliti dan rapi serta terampil dalam mengerjakan tugasnya hingg selesai.

2. Quantity

Kuantitas karyawan dapat dilihat dari penyelesaian tugas tambahan oleh karyawan.

\section{Kerangka Konseptual}

Berikut kerangka konseptual akan dipaparkan dibawah: 


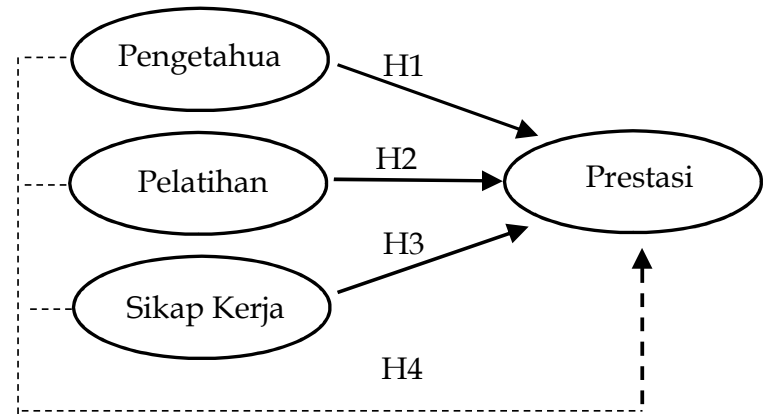

Gambar 1. kerangka konseptual

\section{Hipotesis}

H1 : Pengetahuan memiliki pengaruh pada prestasi kerja karyawan di PT. SENA.

$\mathrm{H} 2$ : Pelatihan memiliki pengaruh pada prestasi kerja karyawan di PT. SENA.

H3 : Sikap kerja memiliki pengaruh tpada prestasi kerja karyawan di PT. SENA.

$\mathrm{H} 4$ : Pengetahuan, pelatihan, dan sikap kerja memiliki pengaruh simultan pada prestasi kerja karyawan di PT. SENA.

\section{METODE PENELITIAN}

\section{Populasi dan Sampel}

Sebanyak 70 karyawan PT SENA dijadikan populasi dan sampel. Sampel jenuh dijadikan sebagai teknik pengambilan sampel. Kuesioner disebar ke responden dan hasil jawaban responden akan dianalisis data dengan analisis regresi linier berganda.

\section{HASIL}

Uji Validitas

Berikut validity test akan dipaparkan sebagai berikut:

\section{Tabel 1}

\begin{tabular}{|c|c|c|}
\hline \multicolumn{3}{|c|}{ Uji Validitas } \\
\hline (V) & $\mathbf{R}_{\text {hitung }}$ & $\mathbf{R}_{\text {tabel }}$ \\
\hline \multirow{6}{*}{$X_{1}$} & .718 & \multirow{6}{*}{$>0.3$} \\
\hline & .591 & \\
\hline & .767 & \\
\hline & .595 & \\
\hline & .833 & \\
\hline & .773 & \\
\hline \multirow{4}{*}{$X_{2}$} & .778 & \multirow{4}{*}{$>0.3$} \\
\hline & 691 & \\
\hline & .808 & \\
\hline & .771 & \\
\hline \multirow{6}{*}{$X_{3}$} & .800 & \multirow{6}{*}{$>0.3$} \\
\hline & .706 & \\
\hline & 656 & \\
\hline & 699 & \\
\hline & .879 & \\
\hline & .815 & \\
\hline \multirow{4}{*}{ Y } & .613 & \multirow{4}{*}{$>0.3$} \\
\hline & .784 & \\
\hline & .783 & \\
\hline & .795 & \\
\hline
\end{tabular}


Dapat dilihat diatas $R_{\text {hitung }}>$ dari $R_{\text {tabel }}$ artinya semua pernyataan pada variabel valid.

\section{Uji Realibilitas}

Berikut akan dipaparkan hasil uji realibilitas:

Tabel 2

Uji Realibilitas

\begin{tabular}{|c|c|c|}
\hline$(\mathrm{V})$ & $\begin{array}{c}\text { Cronbach } \\
\text { Alpha }\end{array}$ & Nilai Kritis \\
\hline$\left(\mathrm{X}_{1}\right)$ & .809 & .60 \\
\hline$\left(\mathrm{X}_{2}\right)$ & .758 & .60 \\
\hline$\left(\mathrm{X}_{3}\right)$ & .855 & .60 \\
\hline$(\mathrm{Y})$ & .727 & .60 \\
\hline
\end{tabular}

Dilihat dari tabel diatas nilai cronbach alpha $>.60$. artinya pernyataan pada semua variabel reliable.

Uji Normalitas

Berikut akan dipaparkan hasil uji normalitas:

Tabel 3

Uji normalitas

\begin{tabular}{|c|c|}
\hline & $\begin{array}{c}\text { Unstandardised } \\
\text { Residual }\end{array}$ \\
\hline $\mathrm{N}$ & 70 \\
\hline Uji Statistik & .080 \\
\hline Asymp.sig(2-tailed) & $.200^{c}$ \\
\hline
\end{tabular}

Apabila nilai asymp.sig .080>.05 diartikan variabel berdistribusi normal.

\section{Uji Multikolinieritas}

Berikut hasil uji multikolinieritas akan disajikan lewat tabel berikut:

Tabel 4

Uji Multikolinieritas

\begin{tabular}{|c|c|c|}
\hline$(\mathrm{V})$ & (Tolerance) & $(\mathrm{VIF})$ \\
\hline$\left(\mathrm{X}_{1}\right)$ & .593 & 1.686 \\
\hline$\left(\mathrm{X}_{2}\right)$ & .645 & 1.551 \\
\hline$\left(\mathrm{X}_{3}\right)$ & .629 & 1.590 \\
\hline
\end{tabular}

Nilai tolerance (>.10) dan (VIF<10.) Maka data diatas tidak terjadi multikolinieritas.

\section{Uji Heteroskedastisitas}

Berikut akan dipaparkan hasil uji hesteroskedastisitas: 


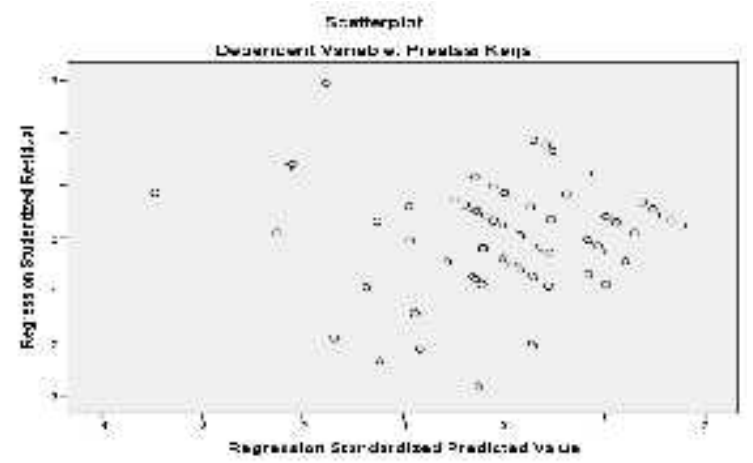

Gambar 2

Uji Hesteroskedastisitas

Dilihat hasil diatas titik tersebar acak dan rata serta tidak ada bentuk pola tertentu artinya tidak terjadi heteroskedastisitas

Uji Autokorelasi

Berikut hasil uji autokorelasi akan disajikan lewat tabel berikut:

Tabel 6

Uji Autokorelasi

\begin{tabular}{|r|}
\hline (DW) \\
\hline 2.034 \\
\hline
\end{tabular}

Nilai (DW 2.034>DU 1.703) artinya tidak terjadi autokorelasi.

(Uji T)

Hasil uji t akan disajikan berikut ini:

Tabel 7

(Uji T)

\begin{tabular}{|c|c|c|}
\hline Koefisien Standar & $(\mathbf{T})$ & $(\mathbf{S i g})$ \\
\hline$\left(\mathrm{X}_{1}\right)$ & 2.061 & .043 \\
\hline$\left(\mathrm{X}_{2}\right)$ & 4.041 & .000 \\
\hline$\left(\mathrm{X}_{3}\right)$ & 2.263 & .027 \\
\hline
\end{tabular}

Dari perhitungan diatas diketahui jika:

1. Variabel $\left(X_{1}\right)$ thitung 2.061 dengan nilai sig .043 . Sehingga $(.043<.05)$ artinya variabel $X_{1}$ memiliki pengaruh pada variabel $\mathrm{Y}$.

2. Variabel $\left(X_{2}\right)$ thitung 4.041 dengan nilai sig .000. Sehingga $(.000>.05)$ artinya variabel $X_{2}$ memiliki pengaruh pada variabel $Y$.

3. Variabel $\left(X_{3}\right)$ thitung 2.263 dengan nilai sig .027 . Sehingga $(.027<.05)$ artinya variabel $X_{3}$ memiliki pengaruh pada variabel $\mathrm{Y}$.

(Uji F)

Hasil uji f akan disajikan berikut:

Tabel 8. 


\begin{tabular}{|c|c|c|}
\multicolumn{1}{|c|}{ (Uji F) } \\
\hline (Model) & (F) & (Sig) \\
\hline Regresi & 26.130 & .000 \\
\hline
\end{tabular}

Dari hasil uji $f$ diatas nilai $f_{\text {hitung }} 26.130$ dengan nilai sig $.000<.05$ artinya variabel $\left(X_{1}\right),\left(X_{2}\right)$ dan $\left(X_{3}\right)$ memiliki pengaruh seacara bersama-sama pada variabel $Y$.

\section{PEMBAHASAN}

1. Pengetahuan memiliki pengaruh yang signifikan dan positif pada Prestasi Kerja. Hasil ini sesuai dengan penelitian dari Dedy Suryani (2013). Hasil ini membuktikan karyawan PT. SENA memiliki pengetahuan yang baik dan luas sehingga dapat bekerja sesuai bidang yang diberikan. Pengetahuan yang dimiliki tiap karyawan juga bisa lebih ditingkatkan karena bisa menjadi asset masa depan perusahaan.

2. Pelatihan memiliki pengaruh yang signifikan dan positif pada Prestasi Kerja. Hasil ini sesuai dengan penelitian dari Yuli Mardiyanti (2017). Pelatihan dan seminat menjadi kunci perusahaan dalam meningkatkan prestasi kerja pelatihan juga harus terus ditingkatkan dengan terus melatih keahlian yang dimiliki karyawan agar dimasa yang akan datang karyawan siap ketika ada masalah yang menerpa.

3. Sikap Kerja memiliki pengaruh yang signifikan dan positif pada Prestasi Kerja. Hasil sesuai penelitian dari Kusuma Marigan dkk (2016). Hasil ini menunjukkan sikap kerja karyawan PT. SENA tergolong baik dan sopan sehingga membantu meningkatkan prestasi kerja. Karyawan yang jujur dan memiliki komitmen yang tinggi akan membuat karyawan berprestasi lebih jauh lagi.

4. Pengetahuan, Pelatihan, dan Sikap Kerja secara bersama-sama memiliki pengaruh yang signifikan dan positif pada Prestasi Kerja. Karyawan yang berprestasi akan memiliki pengetahuan yang luas, sering mengikuti pelatihan dan juga memiliki sikap kerja yang jujur dan amanah.

\section{SIMPULAN}

1. Variabel $(X 1)$ mempunyai pengaruh pada variabel $(Y)$.

Artinya pengetahuan yang luas yang dimiliki karyawan akan membantu meningkatkan prestasi kerja karyawan. Pengetahuan menjadi hal yang penting dimiliki tiap karyawan. Pengetahuan bisa didapat dari saling bertukar pendapat atau ikut dalam seminar-seminar dan kepelatihan yang diikuti oleh karyawan sendiri maupun yang diadakan oleh perusahaan.

2. Variabel (X2) mempunyai pengaruh pada variabel $(\mathrm{Y})$.

Artinya perusahaan yang sering mengikutsertakan karyawannya dalam pelatihan kerja akan semakin membuat karyawan tersebut mampu meningkatkan kemampuan dan prestasi kerja karyawan.

3. Variabel $(X 3)$ mempunyai pengaruh pada variabel $(Y)$.

Artinya sikap kerja karyawan yang disiplin dan mampu mengontrol diri agar tetap tenang dalam menyelesaikan pekerjaan akan semakin mudah dalam membantu meraih prestasi kerja. Perilaku atau sikap kerja karyawan harus tetap dalam pengendalian diri karena didalam pekerjaan pasti aka nada suatu tugas yang berat sehingga karyawan harus tetap terkendali emosi dan tetap tenang agar tugas yang diberikan terselesaikan tepat waktu serta semakin mewujudkan tercapainya prestasi kerja.

4. Variabel (X1), (X2), dan (X3) mempunyai pengaruh simultan pada variabel (Y).

Artinya semakin tinggi pengetahuan yang dimiliki karyawan, banyaknya bentuk pelatihan yang dilakukan perusahaan, dan kontrol sikap kerja yang baik dan tenang akan mendorong tercapainya suatu prestasi kerja karyawan.

\section{IMPLIKASI}

PT. SENA harus menambah berbagai macam pelatihan yang disesuaikan dengan bidang karyawan sehingga akan menambah pengetahuan dan kemampuan para karyawannya. kemudian dalam hal perekrutan karyawan baru harus melihat pengetahuan dan kemampuan calon karyawan agar dalam bekerja 
nanti karyawan tersebut dapat memberikan kontribusi banyak diperusahaan dan mampu meciptakan prestasi kerja.

Sikap kerja karyawan juga perlu diperhatikan. Hal ini dikarenaka sikap atau perilaku karyawan menjadi faktor pendukung tercapainya prestasi kerja karyawan. Sikap kerja karyawan yang disiplin waktu atau ketepatan waktu dalam menyelesaikan tugas akan menjadi prestasi tersendiri bagi karyawan. Kesopanan dalam berbicara dan selalu menjaga etika akan menjadikan kebiasaan yang baik bagi karyawan. Perusahaan yang mempunyai sikap kerja yang baik akan mampu menciptkan kenyamanan dilingkungan kerja serta mendorong peningkatan prestasi pada karyawan.

\section{KETERBATASAN PENELITIAN}

Masih terdapat responden yang menjawab kuisioner tanpa memahami pernyataan terlebih dahulu. Waktu, biaya, dan tenaga yang terbatas menjadi kendala dalam proses pengambilan data.

\section{DAFTAR RUJUKAN}

Azwar, Saifuddin, 2012, Sikap Manusia: Teori dan Pengukurannya. Yogyakarta: Liberty.

Eko, Widodo Suparno. 2015. Manajemen Pengembangan Sumber Daya Manusia, Yogyakarta: Pustaka Pelajar.

Fuadi, F. I., 2016, Hubungan Antara Pengetahuan Dengan Sikap Masyarakat Dalam Mencegah Leptospirosis Di Desa Pabelan Kecamatan Kartasura Kabupaten Sukoharjo, Publikasi Ilmiah, Fakultas IImu Kesehatan, Universitas Muhammadiyah Surakarta.

Hasibuan, Malayu. 2008, Manajemen Dasar, Pengertian, Dan Masalah. Jakarta: PT. Bumi Aksara.

Mangkunegara, Anwar Prabu, 2013. Manajemen Sumber Daya Manusia Perusahaan. Bandung: PT. Remaja Rosda Karya

Mardiyanti, Yuli, 2017, Pengaruh Pendidikan, Pelatihan, Dan Pengalaman Kerja Terhadap Prestasi Kerja Karyawan Pada PT. Sami Surya Perkasa Sukoharjo, Skripsi, Universitas Muhammadiyah Surakarta.

Muhson, Muhammad, Tawardjono Us, 2015, Hubungan Antara Sikap Kerja Dan Motivasi Kerja Dengan Kesiapan Kerja Siswa, E-Jurnal Pendidikan Teknik Otomotif, 19 (2), 155-162, Universitas Negeri Yogyakarta.

Putri, A. A., 2018, Pengaruh Pengetahuan, Keterampilan, Konsep Diri, Karakteristik Pribadi Dan Motif Sumber Daya Manusia Terhadap Prestasi Kerja Karyawan Di Bmt Ugt Sidogiri Se - Surabaya, Skripsi, Universitas Negeri Sunan Ampel Surabaya.

Suhartini, Yati, 2016, Pengaruh Pengetahuan, Keterampilan Dan Kemampuan Karyawan Terhadap Kinerja Karyawan (Studi Pada Industri Kerajinan Kulit Di Manding, Bantul, Yogyakarta), Skripsi, Universitas PGRI Yogyakarta. 